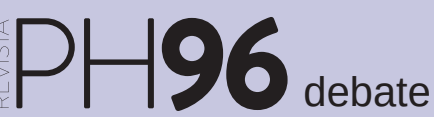

a debate Memoria democrática en la construcción de la historia y el patrimonio

| coordina Josefina Cuesta Bustillo

\title{
Arte silenciado, arte olvidado. La mujer creadora en la etapa franquista
}

\author{
Marcos Serrano-Carrillo | graduado en Bellas Artes \\ Mercedes Molina-Liñán | Dpto. de Historia, Teoría y Composición Arquitectónicas, Universidad de Sevilla \\ URL <http://www.iaph.es/revistaph/index.php/revistaph/issue/view/4344>
}

Cultura y resistencia fueron los vehículos de expresión que determinados artistas emplearon durante el régimen militar español, situación política que marcó la trayectoria creativa de muchas mujeres que supieron desarrollar una mirada artística diferente y personal en un contexto flagrantemente represivo para el mundo cultural.

El arte outsider o marginal, tradicionalmente olvidado, es el resultante del olvido mediático, por lo que se ha centrado en la elaboración de piezas artísticas sin más intención que la del deleite del propio artista, la rebelión, el consuelo o la liberación. Llevado a cabo por artistas cuyo sustento económico procedía en algunos casos de la más absoluta precariedad laboral, las mujeres, a pesar de ser víctimas de la represión del régimen, en su discreto silencio e intimidad adquieren un especial protagonismo creativo que parece haber desmerecido un lugar en la historia.

Profundamente perseguidas fueron, no en pocas ocasiones, condenadas por conductas consideradas "moralmente inaceptables", situación que provocaría el exilio de excepcionales creadoras. Tal es el caso de la española Remedios Varo (1908-1963), pintora compañera de Dalí y Lorca, que sobrevivió como ilustradora eventual en México y que no recibió, hasta cuarenta y cuatro años después de su muerte, un justo reconocimiento. Este se llevó a cabo gracias a la interesante novela que lleva por título La cazadora de astros, de Zoé Valdés, donde se relata la apasionante y desconocida vida de la artista (DIEGO DE, 2007).

O la situación de Josefa Tolrà (1880-1959), conocida como "la Pepeta de Cabrils", humilde campesina cuyos hijos murieron en la Guerra Civil española. Sin nin- gún tipo de formación académica, a la edad de setenta años comenzó a pintar, dibujar y elaborar bordados utilizando la expresión pictórica como elemento catalizador para "conectar con el más allá". Siendo reconocida como "medium", creó una serie de sorprendentes piezas a las que no daba valor real, pero que años después serían considerados como unos de los más importantes referentes de la vanguardia artística del momento en España (GARCIA, 2015).

Esta compleja situación marcará el escenario artístico de numerosas creadoras que, condenadas al ostracismo debido a su condición de mujer librepensadora, se verán obligadas a desarrollar su actividad en el exilio. La vida y obra de estas artistas se vieron directamente influenciadas por el régimen militar español, ya sea por haber sido perseguidas o completamente ignoradas.

El acceso a estudios superiores de la mujer en España era también algo muy complejo debido al rígido sistema social establecido por el franquismo. El ingreso de la primera mujer en una escuela de arte en Europa no se producirá hasta el año 1860 en la Royal Academy de Londres. En Francia no será hasta 1897 y con ciertas limitaciones, pues las clases de dibujo al natural con modelos les estuvieron prohibidas por indecorosas hasta bien avanzado el siglo XX (VAL, 2013).

En España, no sería hasta 1915, cuando abriría la "Residencia de señoritas" en Madrid, liderada por la pedagoga institucionalista María de Maeztu. En esta residencia, estudiarían artistas de importancia vital en el panorama artístico contemporáneo, dirigidas por profesoras como María Goyri, Victorina Durán, María Zambrano o Maruja Mallo. La Residencia fue prohibida 
tras la Guerra Civil, terminando su directora, como tantas otras mujeres, olvidadas y en el exilio (Argentina).

Las dificultades a las que las mujeres artistas han estado expuestas a lo largo de la historia responden a la relegación social a la que han sido habitualmente sometidas. Los conflictos que las creadoras padecían estaban básicamente motivados por su escasa o nula consideración como tales, situación que provocará el exilio, el olvido y la muerte, no solo física sino también artística, de muchas de ellas (MERINO HERNÁNDEZ, 2015).

El arte outsider en España, más en concreto el arte de la mujer, no sería reconocido públicamente hasta finales del siglo XX y lo fue gracias a la exposición "Visiones Paralelas, Artistas Modernos y Arte Marginal", realizada en el museo Reina Sofía en el año 1993 (GARCíA, 2010). Esto abriría un nuevo campo de interés hacia los artistas que prosperan al margen del mercado y de lo académico. Su sinceridad creativa y el vivo paralelismo vivencial que representan no pasaría desapercibido por los expertos, aunque de momento son grandes desconocidas.

A pesar de contar con unos importantes referentes españoles, aún encontramos en ese sentido un importante vacío en el arte outsider desarrollado por la mujer española. Aun siendo motivo de referencia en artículos periodísticos y otros medios de comunicación, consideramos que sus obras permanecen en gran medida ocultas, siendo en este momento muy dificultosa la búsqueda de referencias importantes sobre dichas artistas.

Entre la cantidad de artistas españolas que tuvieron que migrar al extranjero, un gran porcentaje eran mujeres de las que por el momento poco o nada se ha hablado. Nombres como Ángeles Santos (1911-2013), Carmen de Burgos (1867-1932), Julia Minguillón (1906-1965), Marga Gil Roesset (1908-1932), a los que le seguirían una larga lista de artistas y activistas españolas que sistemáticamente han permanecido silenciadas y olvidadas, cuyas obras podrían aportar un rico patrimonio al panorama artístico e intelectual de España y de Europa.

\section{BIBLIOGRAFÍA}

- DIEGO DE, E. (2007) Remedios Varo. Madrid: Fundación Mapfre, 2017

- GARCÍA, G. (2015) Arte outsider: la pulsión creativa al desnudo. Barcelona: Sans Soleil, 2015

- GARCÍA MUÑOZ, G. (2010) Procesos creativos en artistas outsider. Madrid: Universidad Complutense de Madrid, 2010

- MERINO HERNÁNDEZ, R. (2015) La Residencia de Señoritas y otras redes culturales femeninas. Salamanca: Ediciones Universidad de Salamanca, 2015

- VAl CuBero, A. (2013) La profesionalización de las mujeres artistas españolas. El caso de Maruja Mallo (19021995) y Amalia Avia (1926-2011). Papers, revista de sociología, vol. 98, (n. $\left.{ }^{\circ} 4\right), 2013$

\section{Nota}

Cuando esta contribución llegó, el artículo introductorio de esta sección a cargo de la coordinadora Josefina Cuesta estaba ya cerrado, de ahí que no se haga alusión a él. 